\title{
The role of taurine derivatives in the putative therapy of COVID-19-induced inflammation
}

\author{
OC Iwegbulem $^{1 *}$, JH Wang ${ }^{1}$, RW Pfirmann ${ }^{2}$ and HP Redmond ${ }^{1}$ \\ ${ }^{1}$ Department of Academic Surgery, University College Cork, Cork University Hospital, Ireland \\ ${ }^{2}$ Former Assistant to Prof. H. Lettré, Exp. Cancer Research Institute Heidelberg, Switzerland
}

\section{The pathologic process in COVID-19}

The novel coronavirus disease (COVID-19) named by the World Health organization (WHO) as a global pandemic was discovered through a series of viral pneumonia cases associated with fever, cough and dyspnoea in Wuhan, China [1]. With over 700,000 deaths worldwide, current medical management is still supportive, while definite treatment of prophylactic vaccine or therapeutic drugs that are specific to COVID-19 is underway. The dominant mechanism of host cell entry by COVID-19 is via angiotensin-converting enzyme-2 (ACE-2) receptor expressed by epithelial cells of the lung, intestine, kidney, and blood vessels [2]. Like the SARS-CoV and MERS-CoV, COVID-19 dysregulates innate immune viral response via inhibition of interferons (INFs) produced in infected alveolar epithelial cells [1,2]. This leads to accumulated monocyte/macrophage load and the activation of NF- $\kappa \mathrm{B}$ that triggers over-production and release of proinflammatory mediators such as IL- $1 \beta$, IL- 6 , GM-CSF, TNF- $\alpha$, CXC-chemokine ligand 8 (CXCL-8), CXCL-10, CC-chemokine ligand 2 (CCL-2) and CCL-3 $[1,2]$ with a consequent phenomenon of the cytokine release storm (CRS). CRS is thought to be the major cause of disease severity and death in COVID-19 patients.

\section{Potential role of IL-6 in COVID-19-induced inflammation}

High circulating IL-6 levels are associated with disease severity, hospitalization, ICU admission and poor prognosis with higher risk of respiratory failure. A number of studies have shown that patients with severe COVID-19 infection display high serum/plasma IL-6 levels with lymphopenia [3]. Critically, an elevated IL-6 is an independent risk factor for development of sepsis and progression to critical illness in COVID-19 patients $[1,3]$. It is hypothesized that IL- 6 and Fas-FasL interaction are primarily responsible for lymphocyte apoptosis observed in autopsy of spleen and lymph nodes from patients who died from COVID-19 [3]. Across the world, a large number of anti-IL-6 clinical trials are in progress for IL-6 blockade following some benefit [1-3].

\section{Taurine}

The importance of taurine, a ubiquitous essential amino-acid, has been demonstrated in many biological processes and milieu such as oxidation, cell homeostasis and bile salt formation [4].Taurine in humans is found endogenously in body fluids, heart, retina, skeletal muscle, brain, and of high concentration in leukocytes. Taurine naturally occurs in seafood and meat. It has been supplemented in infant formula containing meals and health drinks and are sold worldwide for treatment of various conditions and to improve general wellbeing [4]. In inflammatory settings such as trauma, sepsis and critical illness, the relevance for taurine is emphasized as the body systems have increasing requirements and a reduced anti-inflammatory protection. A decrease in taurine levels has been correlated with deranged metabolic pattern both in feline and human studies. With its acceptable properties and demonstrated therapeutic effect, taurine is used as a base compound for many derivatives.

\section{Taurine derivatives}

Taurolidine (TRD) is a taurine N-methylol derivative with broad spectrum bactericidal activity and is commonly used in Europe and USA as adjunct therapy in a variety of infections in humans. TRD metabolizes totaurine as the active metabolite with $\mathrm{N}$-methylol derivatives taurultam (TRLT) and taurinamide, which block the gram-negative bacterial cell wall component lipopolysaccharide (LPS) irreversibly. TRD downregulates inflammation through inhibition of proinflammatory cytokines TNF- $\alpha$, IL-1 $\beta$, IL- 6 and IL- 8 in peripheral blood mononuclear cells (PBMCs). This is an added effect in its multimodal antimicrobial activity against antibiotic multi-resistant bacteria. The clinical benefit of TRD in excessive inflammatory conditions has been demonstrated in the perioperative setting [5,6]. In the S.U.R.G.U.V.A.N.T trial, we demonstrated that TRD attenuated IL-6 levels over a 7-day period following surgery-induced inflammatory changes on perioperative tumor dynamics that would normally result in pro-inflammatory cytokine surge [5]. Dodakkula et al. [6] showed that TRD inhibits proinflammatory cytokine IL-6 release following coronary artery bypass surgery. Taurine provides a cyto-prophylactic role in its reaction with $\mathrm{HOCl}$ generated via MPO pathway in PBMCs to form taurine chloramine, and in turn, taurine chloramine inhibits the activation of NF- $\kappa \mathrm{B}$ which is a potent signal transducer for proinflammatory cytokine production $[7,8]$.

A novel taurine derivative 1.4.5-Oxathiazinane-4,4-dioxide (OTD) is an aliphatic sulfonamide and also a structural analogue of TRLT. It has a longer half-life and like TRD, it can be administered via topical, intravenous and intraperitoneal routes as well as orally. Both compounds are well-tolerated drugs with high safety profile and no adverse effects except peripheral vein irritation when TRD is given at high doses $[5,6]$. OTD causes less burning pain when given intravenously [7].

${ }^{\star}$ Correspondence to: OC Iwegbulem, Department of Academic Surgery, University College Cork, Cork University Hospital, Cork, Ireland; E-mail: ogeiwems@yahoo.com

Key words: taurine, COVID-19, inflammation

Received: November 12, 2019; Accepted: November 24, 2020; Published: November 01, 2020 


\section{Future potential therapy targeting IL-6 using taurine derivatives}

With the world's current focus being on developing definite therapeutics, the issue of cytokine storm plaguing COVID-19 infection needs to be addressed. The proinflammatory process contributing to cytokine storm substantiates the need for targeted immune-suppressive treatment.

The efficacy of Taurine derivatives as an infection barrier is well documented in literature and we believe its putative anti-inflammatory role should be regarded as a promising available therapeutic approach in COVID-19 patient management, for which minimal to no side effects are known.

\section{References}

1. Merad M, Martin JC (2020) Pathological inflammation in patients with COVID-19: a key role for monocytes and macrophages. Nat Rev Immunol 20: 355-362. [Crossref]

2. Azkur AK, Akdis M, Azkur D, Sokolowska M, van de Veen W, et al. (2020) Immune response to SARS-CoV-2 and mechanisms of immunopathological changes in COVID-19. Allergy 75: 1564-1581. (2020). [Crossref]
3. Vabret N, Britton GJ, Gruber C, Hegde S, Kim J, et al. (2020) Immunology of COVID-19: current state of the science. Immunity 52: 910-941. [Crossref]

4. Schuller-Levis GB, Park E (2003) Taurine: new implications for an old amino acid. FEMS Microbiol Lett 226: 195-202. [Crossref]

5. Redmond HP, Neary PM, Jinih M, O'Connell E, Foley N, et al. (2018) RandomiSed clinical trial assessing use of an anti-inflammatory agent in attenuating perioperative inflammation in non-metastatic colon cancer - the surguvant trial. BMC Cancer 18: 794. [Crossref]

6. Doddakula KK, Neary PM, Wang JH, Sookhai S, O'Donnell A, et al. (2010) The antiendotoxin agent taurolidine potentially reduces ischemia/reperfusion injury through its metabolite taurine. Surgery 148: 567-572. [Crossref]

7. Kichko TI, Pfirrmann RW, Reeh PW (2016) Taurolidine and congeners activate hTRPA1 but not hTRPV1 channels and stimulate CGRP release from mouse tracheal sensory nerves. Pharmacol Res Perspect 4: e00204. [Crossref]

8. Marcinkiewicz J, Kurnyta M, Biedroń R, Bobek M, Kontny E, et al. (2006) Anti-inflammatory effects of taurine derivatives (taurine chloramine, taurine bromamine, and taurolidine) are mediated by different mechanisms. Adv Exp Med Biol 583: 481-492. [Crossref]

Copyright: $(2020$ Iwegbulem OC. This is an open-access article distributed under the terms of the Creative Commons Attribution License, which permits unrestricted use, distribution, and reproduction in any medium, provided the original author and source are credited. 